\title{
FAKTOR-FAKTOR YANG MEMENGARUHI MINAT MAHASISWA ASAL LUAR BALI KULIAH DI FMIPA UNIVERSITAS UDAYANA BALI
}

\author{
Daimatul Khoiriyah ${ }^{1}$, Made Susilawati ${ }^{2}$, Desak Putu Eka \\ NILAKUSMAWATI ${ }^{3}$ \\ 1,2,3 Jurusan Matematika FMIPA Universitas Udayana, Bukit Jimbaran 80361,

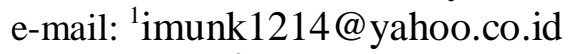 \\ ${ }^{2}$ susilawati.made@gmail.com, ${ }^{3}$ nilakusmawati_desak@yahoo.com
}

\begin{abstract}
Abstrak
Tujuan dari penelitian ini adalah untuk mengetahui faktor-faktor yang memengaruhi minat mahasiswa luar Bali kuliah di FMIPA Universitas Udayana Bali. Analisis yang digunakan dalam penelitian ini adalah analisis faktor. Data yang digunakan adalah data primer yang diperoleh dengan menyebarkan kuesioner kepada setiap mahasiswa asal luar Bali yang kuliah di FMIPA Universitas Udayana Bali angkatan 2008-2011. Dalam penelitian ini faktor-faktor yang digunakan adalah lokasi, faktor biaya, produk, latar belakang sosial ekonomi, motivasi, fasilitas, referensi, promosi, dan reputasi. Hasil penelitian menunjukkan bahwa, terdapat delapan faktor yang memengaruhi minat mahasiswa luar Bali kuliah di FMIPA Universitas Udayana Bali. Faktor tersebut yaitu: (1) faktor produk yang merupakan faktor dengan nilai eigen paling tinggi yaitu 7,792 dan varian $28,860 \%$, (2) faktor referensi dengan varian $8,732 \%$, (3) faktor reputasi dengan varian 7,808\%, (4) faktor biaya dengan varian 6,723\%, (5) faktor latar belakang sosial ekonomi dengan varian 4,921\%, (6) faktor motivasi dengan varian 4,430\%, (7) faktor lokasi dengan varian 3,836\% dan (8) faktor promosi dengan varian $3,708 \%$, dengan total varian yang dapat dijelaskan adalah sebesar $69,018 \%$.
\end{abstract}

Keywords: Analisis Faktor, Minat Mahasiswa, Minat Kuliah, Kuliah

\section{Pendahuluan}

Menurut UU No. 20 Tahun 2003, pendidikan adalah usaha sadar dan terencana untuk mewujudkan suasana belajar dan proses pembelajaran agar peserta didik secara aktif mengembangkan potensi dirinya untuk memiliki kekuatan spiritual keagamaan, pengendalian diri, kepribadian, kecerdasan, akhlak mulia serta keterampilan yang diperlukan dirinya, masyarakat, bangsa dan negara. Setiap warga negara Indonesia mempunyai hak yang sama untuk memperoleh pendidikan yang baik dan bermutu sehingga dapat meningkatkan wawasan warga negara. Pemerintah wajib memberikan layanan dan kemudahan serta jaminan terselenggaranya pendidikan yang bermutu bagi setiap warga negara. Pendidikan tidak hanya berguna untuk meningkatkan kualitas hidup manusia, tetapi juga diharapkan dapat merubah pola pikir masyarakat yang demokratis.

\footnotetext{
1 Alumni Mahasiswa Jurusan Matematika FMIPA Universitas Udayana

${ }^{2,3}$ Staf Pengajar Jurusan Matematika FMIPA Universitas Udayana
} 
Perguruan tinggi merupakan salah satu sarana dalam penyelenggaraan dan pengembangan pendidikan yang dapat meningkatkan mutu kehidupan masyarakat, bangsa dan negara. Sistem pendidikan nasional harus mampu menjamin pemerataan kesempatan pendidikan dan peningkatan mutu pendidikan untuk menghadapi tantangan sesuai dengan tuntutan perubahan kehidupan lokal, nasional dan global sehingga perlu dilakukan pembaharuan pendidikan secara terencana, terarah dan berkesinambungan. Dengan demikian perguruan tinggi di Indonesia sangat diharapkan mampu meningkatkan kualitas hidup manusia.

Terdapat banyak perguruan tinggi yang mempunyai program S1 di Indonesia. Perguruan tinggi dapat berbentuk akademi, politeknik, sekolah tinggi, institut atau universitas. Kemampuan untuk memperoleh mahasiswa tergantung dari penyampaian informasi atau promosi tentang perguruan tinggi yang bersangkutan. Perguruan tinggi sebagai penyedia produk berupa jasa pendidikan harus mampu mengenali target pasar yang menjadi sasarannya. Salah satu perguruan tinggi di Indonesia adalah Universitas Udayana yang terletak di pulau Bali. Universitas Udayana mempunyai peluang yang sama dengan perguruan tinggi yang lain untuk dipilih oleh calon mahasiswa dalam melanjutkan studinya. Universitas Udayana memiliki 12 fakultas, salah satunya adalah Fakultas Matematika dan Ilmu Pengetahuan Alam (FMIPA). Terdapat enam jurusan di FMIPA yaitu, fisika, kimia, biologi, matematika, farmasi dan ilmu komputer. Fakultas ini merupakan salah satu fakultas yang banyak diminati oleh calon mahasiswa.

Banyak masyarakat Bali dan luar Bali yang memilih kuliah di FMIPA Universitas Udayana dari pada Universitas lain yang berada di luar Bali. Padahal Universitas yang berada di luar Bali juga memiliki kualitas yang tidak berbeda jauh dengan FMIPA Universitas Udayana. Dari data mahasiswa yang diperoleh, jumlah mahasiswa asal luar Bali yang masih aktif kuliah di FMIPA Universitas Udayana Tahun 2008 sebanyak 18 orang, Tahun 2009 sebanyak 44 orang dan pada Tahun 2010 sebanyak 59 orang. Dapat dilihat dari data tersebut bahwa jumlah mahasiswa asal luar Bali yang kuliah di FMIPA Universitas Udayana tiap tahunnya meningkat. Apabila ditinjau dari mahasiswa, secara umum terdapat beberapa faktor yang melatarbelakangi mahasiswa dalam menentukan pilihannya memilih universitas. Menurut Harahap [3], faktor-faktor yang memengaruhi keputusan mahasiswa dalam menempuh pendidikan adalah proses, biaya, latar belakang sosial ekonomi, motivasi, fasilitas, referensi, lokasi, promosi, reputasi dan alumni.

Pada penelitian ini diperlukan analisis untuk menentukan faktor-faktor tersebut. Ada beberapa analisis yang dapat menyelesaikan penelitian tersebut seperti analisis regresi linear berganda, regresi logistik dan analisis faktor. Analisis regresi linear berganda digunakan untuk melihat hubungan dan pengaruh antara satu atau lebih variabel bebas terhadap satu variabel tidak bebas. Dalam penggunaan analisis regresi linear berganda terdapat beberapa asumsi yang harus dipenuhi seperti kehomogenan ragam dan kenormalan sisaan dengan variabel tidak bebas minimal berskala interval atau rasio. Regresi logistik merupakan 
pendekatan matematika yang digunakan untuk menggambarkan hubungan dari beberapa variabel bebas dengan variabel tidak bebas kategorik. Sedangkan analisis faktor bertujuan untuk mengidentifikasi adanya hubungan antar variabel. Dalam analisis ini tidak dibedakan variabel bebas dan variabel tidak bebasnya. Berdasarkan uraian tersebut, maka penulis tertarik untuk melakukan penelitian yang berjudul "Faktor-faktor yang Memengaruhi Minat Mahasiswa Asal Luar Bali Kuliah di FMIPA Universitas Udayana Bali”.

Analisis faktor merupakan salah satu metode statistika multivariat yang digunakan untuk menemukan beberapa faktor yang mendasari dan menerangkan hubungan diantara variabel. Analisis faktor adalah sebuah teknik yang digunakan untuk mencari faktor-faktor yang mampu menjelaskan hubungan atau korelasi antara berbagai indikator independen yang diobservasi.

Menurut Hair et al [2], analisis faktor adalah sebuah nama umum yang diberikan kepada sebuah kelas dari metode statistika multivariat yang tujuan utamanya adalah menentukan struktur yang mendasari keterkaitan (korelasi) antara sejumlah variabel. Prinsip dasar dari analisis faktor yaitu dengan mengekstrasi sejumlah faktor dari gugusan variabel asal $X_{1}, X_{2}, \cdots, X_{p}$ sehingga banyaknya factor lebih sedikit dari banyaknya variabel asal $X$ dan sebagian besar informasi (ragam) variabel asal $X$ tersimpan dalam sejumlah faktor.

Langkah pertama dalam analisis faktor adalah menghitung matriks korelasi untuk mengetahui syarat kecukupan bagi data di dalam analisis faktor. Metode Kaiser-Meyer Olkin (KMO) paling banyak digunakan untuk melihat syarat kecukupan data untuk analisis faktor. Metode ini mengukur kecukupan sampling secara menyeluruh dan mengukur kecukupan sampling untuk setiap indikator. Metode ini mengukur homogenitas indikator. Rumus untuk menghitung KMO sebagai berikut:

$$
K M O=\frac{\sum \sum_{i=j} r_{i j}^{2}}{\sum \sum_{i=j} r_{i j}^{2}+\sum \sum_{i=j} a_{i j}^{2}}
$$

dengan:

$r_{i j}^{2}=$ koefisien korelasi

$a_{i j}^{2}=$ koefisien korelasi parsial

Secara umum tingginya KMO sangat diperlukan. Disarankan untuk paling tidak di atas 0,80. Namun, di atas 0,5 biasanya masih bisa diakomodasi untuk penentuan analisis faktor.

Selain memasukkan semua indikator di dalam perhitungan korelasi, KaiserMeyer Olkin juga menghitung koefisien korelasi di dalam analisis faktor untuk indikator tertentu. Adapun formulanya sebagai berikut:

$$
M S I_{i}=\frac{\sum r_{i j}^{2}}{\sum r_{i j}^{2}+\sum a_{i j}^{2}}
$$


Keterangan:

$r_{i j}=$ koefisien korelasi

$a_{i j}=$ koefisien korelasi parsial

Sebagaimana KMO, semakin tinggi nilai koefisien korelasi MSA maka sangat beralasan untuk memasukkan indikator secara individual di dalam analisis faktor. Uji Bartlett's test of shericity merupakan uji statistik untuk signifikansi menyeluruh dari semua korelasi di dalam matriks korelasi.

Setelah terpenuhi syarat kecukupan data, maka langkah selanjutnya adalah mencari faktor atau ekstraksi faktor (extracting faktor). Ekstraksi faktor adalah suatu metode yang digunakan untuk mereduksi data dari beberapa indikator untuk menghasilkan faktor yang lebih sedikit yang mampu menjelaskan korelasi antar indikator yang diobservasi. Ada beberapa metode yang bisa digunakan untuk melakukan ekstraksi faktor yaitu principal component analisis, principal axis factoring, unweighted leastsquares, generalized least squares dan maximum likelyhood. Metode ekstraksi faktor yang digunakan pada penelitian ini adalah metode Principal Components Analysis (analisis komponen utama).

Analisis Komponen Utama (AKU) atau Principle Component Analysis yang merupakan suatu teknik analisis untuk mentransformasi variabel-variabel asli yang masih saling berkorelasi satu dengan yang lain menjadi satu set variabel baru yang tidak berkorelasi lagi. Variabel-variabel baru itu disebut sebagai komponen utama (Principal Component).

Secara umum model analisis faktor (Johnson dan Wichern, [4]) adalah:

$$
\begin{gathered}
X_{1}-\mu_{1}=l_{11} F_{1}+l_{12} F_{2}+\cdots+l_{1 m} F_{m}+\varepsilon_{1} \\
X_{2}-\mu_{2}=l_{21} F_{1}+l_{22} F_{2}+\cdots+l_{2 m} F_{m}+\varepsilon_{2} \\
\vdots \\
X_{p}-\mu_{p}=l_{p 1} F_{1}+l_{p 2} F_{2}+\cdots+l_{p m} F_{m}+\varepsilon_{p}
\end{gathered}
$$

Dimana $X_{1}, X_{2}, \cdots, X_{p}$ adalah variabel asal ke-1 sampai ke-p, $\mu_{1}, \mu_{2}, \cdots, \mu_{p}$ adalah rataan dari vektor acak ke-1 sampai ke-p, $l_{11}, l_{12}, \cdots, l_{P_{m}}$ adalah bobot (loading)variabel ke-1 sampai ke-m, $F_{1}, F_{2}, \cdots, F_{m}$ adalah faktor ke-1 sampai ke$\mathrm{m}, \varepsilon_{1} \varepsilon_{2}, \cdots \varepsilon_{p}$ adalah galat atau faktor spesifik (specific factor) untuk variabel ke-1 sampai ke-p.

Persamaan (1) juga dapat ditulis dalam bentuk matriks berikut:

$$
\begin{aligned}
& X_{(p \times l)}-\mu_{(p \times l)}=L_{(p \times m)} F_{(m \times l)}+\varepsilon_{(p+l)} \\
& {\left[\begin{array}{c}
X_{1}-\mu_{1} \\
X_{2}-\mu_{2} \\
X_{3}-\mu_{3} \\
X_{p}-\mu_{p}
\end{array}\right]_{(p \times l)}=\left[\begin{array}{ccccc}
l_{11} & l_{12} & l_{13} & \cdots & l_{1 m} \\
l_{21} & l_{22} & l_{23} & \cdots & l_{2 m} \\
l_{31} & l_{32} & l_{33} & \cdots & l_{3 m} \\
\cdots & \cdots & \cdots & \cdots & \cdots \\
l_{p 1} & l_{p 2} & l_{p 3} & \cdots & l_{p m}
\end{array}\right]_{(p \times m)}\left[\begin{array}{c}
F_{1} \\
F_{2} \\
F_{3} \\
\cdots \\
F_{m}
\end{array}\right]_{(m \times l)}+\left[\begin{array}{c}
\varepsilon_{1} \\
\varepsilon_{2} \\
\varepsilon_{3} \\
\cdots \\
\varepsilon_{m}
\end{array}\right]_{(p \times l)}}
\end{aligned}
$$


Dengan:

$\mathrm{X}=$ Vektor variabel asal

$\mathrm{L}=$ Matriks faktor pembobot

$\mathrm{F}=$ Vektor faktor bersama

$\varepsilon=$ Vektor faktor spesifik

$\mu=$ Rata-rata dari vektor $\mathrm{X}$

Model analisis faktor pada persamaan (2) membawa implikasi struktur koragam untuk $X$ menjadi:

$$
\begin{aligned}
& \operatorname{Cov}(\mathrm{X})=\mathrm{LL}^{\prime}+\psi \\
& \operatorname{Cov}(\mathrm{X}, \mathrm{F})=\mathrm{L}
\end{aligned}
$$

Hubungan antara varian variabel asal dengan varians faktor dan varians error adalah sebagai berikut :

$$
\begin{aligned}
\operatorname{Var}\left(X_{i}\right)=\text { communality }+ & \text { specific variance } \\
& =h_{i}^{2}+\psi \\
& =\left(l_{i 1}^{2}+l_{i 2}^{2}+l_{i 3}^{2}+\cdots+l_{i m}^{2}\right)+\psi
\end{aligned}
$$

Berdasarkan persamaan (5) terlihat bahwa $\operatorname{Var}\left(X_{i}\right)$ diterangkan oleh dua komponen yaitu $h_{i}^{2}+\psi . \quad h_{i}^{2}$ disebut komunalitas (communality) yang menunjukkan proporsi keragaman $X_{i}$ yang diterangkan oleh $m$ faktor bersama, dengan $h_{i}^{2}$ merupakan jumlah kuadrat dari bobot factor vektor acak $X_{i}$ pada $m$ factor bersama. Sedangkan $\psi$ disebut sebagai ragam spesifik (specific variance) yang merupakan proporsi ragam dari vektor acak $X_{i}$ yang disebabkan oleh faktor spesifiknya.

Langkah ketiga adalah rotasi faktor yaitu mencari faktor yang mampu mengoptimalkan korelasi antar indikator yang diobservasi. Rotasi faktor ini diperlukan jika metode ekstraksi faktor belum menghasilkan komponen faktor utama yang jelas. Tujuan dari rotasi faktor adalah agar dapat memperoleh struktur factor yang lebih sederhana agar mudah diinterpretasikan.

Pada analisis faktor terdapat dua tipe rotasi yaitu, rotasi orthogonal dan rotasi oblique (Johnson dan Wichern, [4]). Rotasi orthogonal adalah rotasi faktor yang mengekstraksi faktor dengan cara merotasikan sumbu faktor yang kedudukannya saling tegak lurus satu dengan yang lainnya. Prosedur rotasi orthogonal dengan mengasumsikan bahwa secara matematis faktor yang ada bebas dan rotasi harus tegak lurus dengan sudut $90^{\circ}$. Bagian dari rotasi orthogonal yang biasa digunakan adalah Varimax, Quartimax dan Equamax (Hair, et al, [2]).

Rotasi oblique adalah rotasi yang mengekstraksi faktor dengan merotasikan sumbu faktor yang kedudukannya saling membentuk sudut dengan besar sudut tertentu. Rotasi oblique diasumsikan bahwa variabel-variabel yang digunakan tidak dapat dipisahkan atau saling berkorelasi, yang termasuk rotasi oblique adalah oblimin, promax, dan orthobloque. Agar dapat melakukan interpretasi terhadap factor dari hasil rotasi faktor, yang harus diperhatikan adalah besar factor loading dari setiap faktor pada masing-masing variabel. Masingmasing variabel tersebut akan dikelompokkan menjadi satu faktor. 
Untuk tujuan pengelompokan, maka tahapan selanjutnya adalah mencari skor faktor. Skor faktor adalah ukuran individual pada faktor yang mer upakan nilai ratarata terbobot, dan bobot yang diberikan itu sesuai dengan besarnya muatan faktor. Penentuan pembentukan faktor dapat dilakukan dengan melakukan (cut off) atau pemotongan terhadap skor faktor yang dirotasi. Pemotongan didasarkan pada nilainilai tertentu yang didasarkan pada sampel. Dapat dilihat pada tabel berikut:

Tabel 1. Pemotongan (cut off)

\begin{tabular}{|c|c|c|c|}
\hline $\begin{array}{c}\text { Skor } \\
\text { loading }\end{array}$ & $\begin{array}{c}\text { Ukuran sampel yang } \\
\text { dibutuhkan untuk } \\
\text { signifikansi }\end{array}$ & Skor faktor & $\begin{array}{c}\text { Ukuran sampel yang } \\
\text { dibutuhkan untuk } \\
\text { signifikansi }\end{array}$ \\
\hline 0.30 & 350 & 0.55 & 100 \\
\hline 0.35 & 250 & 0.60 & 85 \\
\hline 0.40 & 200 & 0.65 & 70 \\
\hline 0.45 & 150 & 0.70 & 60 \\
\hline 0.50 & 120 & 0.75 & 50 \\
\hline
\end{tabular}

Sumber: Hair, et al [2]

\section{Metode Penelitian}

Penelitian ini dilakukan di FMIPA Universitas Udayana, pada bulan September-November 2011. Data yang digunakan adalah data primer yang merupakan pendapat mahasiswa asal luar Bali yang memilih kuliah di FMIPA Universitas Udayana. Sampel dalam penelitian ini adalah mahasiswa asal luar Bali yang masih aktif kuliah di FMIPA Universitas Udayana yaitu angkatan 20082011. Pengambilan sampel dilakukan dengan cara tidak acak atau non probability sampling yaitu dengan metode purposive sampling.

Penelitian ini mengadaptasi beberapa faktor dan variabel menurut Kotler [5], Harahap [3] dan Nasution (2007) untuk menyesuaikan dengan lokasi dan kondisi dari objek penelitian ini. Faktor yang dipergunakan dari Kotler [5] adalah faktor sosial dengan variabel keluarga dan faktor pribadi dengan variabel keadaan ekonomi. Faktor yang dipergunakan dari Harahap [3] adalah faktor biaya dengan variabel biaya pendaftaran, biaya hidup dan biaya pendidikan, faktor latar belakang sosial ekonomi dengan variabel tingkat pendapatan orang tua, tingkat pendidikan orang tua dan pekerjaan orang tua, faktor motivasi dengan variabel meningkatkan pengetahuan, berprestasi, keinginan orang tua dan kemudahan mendapatkan pekerjaan, faktor fasilitas dengan variabel perpustakaan, laboratorium dan komputer, faktor referensi dengan variabel informasi dari keluarga dan informasi dari rekan, faktor lokasi, faktor promosi dengan variabel Penggunaan iklan di media masa dan elektronik, penggunaan brosur sebagai media informasi dan penggunaan website, faktor reputasi dengan variabel status akreditasi dan faktor alumni. Variabel pada faktor lokasi dalam Harahap [3] berbeda dengan variabel dalam penelitian ini karena untuk menyesuaikan dengan kondisi objek penelitian dan faktor alumni dalam penelitian ini dimasukkan sebagai variabel pada faktor referensi. Sedangkan factor yang dipergunakan dari 
Nasution (2007) adalah faktor produk dengan variable jurusan yang ditawarkan, program beasiswa yang diberikan kepada calon mahasiswa, akreditasi dan program pendidikan disediakan sesuai dengan kebutuhan dunia kerja.

Dimensi penelitian yang digunakan adalah: (1) Lokasi adalah berdasarkan keadaan pariwisata dan kebudayaan yang ada di Bali; (2) Biaya adalah segala biaya yang dikeluarkan mahasiswa dalam menempuh pendidikan di FMIPA Universitas Udayana; (3) Produk adalah jasa yang ditawarkan pada mahasiswa di FMIPA Universitas Udayana; (4) Latar belakang sosial ekonomi adalah hal-hal yang melatar belakangi keadaan sosial ekonomi mahasiswa di FMIPA universitas Udayana; (5) Motivasi adalah hal-hal yang mendorong mahasiswa untuk meneruskan pendidikan di FMIPA Universitas Udayana; (6) Fasilitas adalah ketersediaan fasilitas yang dimiliki oleh FMIPA Universitas Udayana; (7) Referensi adalah referensi yang diterima mahasiswa untuk memilih pendidikan; (8) Promosi adalah upaya dari pihak kampus untuk memberikan informasi pada mahasiswa; (9) Reputasi, berdasarkan persepsi mahasiswa tentang FMIPA Universitas Udayana.

\section{Hasil dan Pembahasan}

Pengujian validitas dan reliabilitas kuesioner dilakukan dengan menyebarkan kuesioner terlebih dahulu kepada 30 mahasiswa asal luar Bali yang kuliah di FMIPA Universitas Udayana. Uji yang dilakukan menyatakan bahwa kuisioner valid dan reliable. Uji kelayakan data dilakukan untuk melihat apakah data yang diperoleh layak untuk diolah dengan menggunakan analisis faktor. Hal ini dapat diketahui dengan menggunakan uji KMO dan uji Bartlett. Jika nilai KMO di atas 0,5 dan uji Bartlett dengan signifikansi kurang dari taraf nyata $(\alpha)$ yang ditentukan maka dianggap memenuhi sehingga analisis faktor sah digunakan.

\section{Penentuan Jumlah Faktor}

Untuk mengetahui faktor yang memengaruhi minat mahasiswa asal luar Bali yang kuliah di FMIPA Universitas Udayana digunakan kriteria nilai eigen. Nilai eigen untuk setiap variabel dapat dilihat pada tabel 2.

Tabel 2. Nilai Eigen

\begin{tabular}{|c|c|c|c|}
\hline Komponen & Akar ciri & Varian (\%) & Kumulatif (\%) \\
\hline 1 & 7,792 & 28,860 & 28,860 \\
\hline 2 & 2,358 & 8,732 & 37,592 \\
\hline 3 & 2,108 & 7,808 & 45,401 \\
\hline 4 & 1,815 & 6,723 & 52,124 \\
\hline 5 & 1,329 & 4,921 & 57,045 \\
\hline 6 & 1,196 & 4,430 & 61,475 \\
\hline 7 & 1,036 & 3,836 & 65,311 \\
\hline 8 & 1,001 & 3,708 & 69,019 \\
\hline
\end{tabular}

Sumber: Data Diolah, 2011 
Pada tabel 2 terlihat bahwa terdapat 8 komponen utama yang memiliki nilai eigen lebih besar dari satu dengan persentase varian yang dijelaskan adalah $28,860 \%$, $8,732 \%, 7,808 \%, 6,723 \%, 4,921 \%, 4,430 \%, 3,836 \%$ dan 3,708\%. Sehingga total varian yang dijelaskan adalah sebesar $69,018 \%$.

\section{Rotasi Faktor}

Rotasi faktor dilakukan untuk mencari faktor yang mampu mengoptimalkan korelasi antar indikator yang diobservasi. Pada analisis ini, rotasi faktor yang digunakan adalah rotasi faktor promax. Nilai loading factor yang digunakan adalah lebih besar dari 0,5.

Terdapat delapan faktor yang memengaruhi minat mahasiswa asal luar Bali Kuliah di FMIPA Universitas Udayana. Berikut adalah pengelompokan dari kedelapan faktor tersebut:

Tabel 3. Pengelompokan Delapan Faktor dari Analisis Faktor

\begin{tabular}{|c|c|c|}
\hline Faktor & $\begin{array}{l}\text { No } \\
\text { Item }\end{array}$ & Variabel \\
\hline \multirow[t]{7}{*}{1} & 10 & Program studi sesuai keinginan mahasiswa \\
\hline & 31 & $\begin{array}{l}\text { Jangka waktu penyelesaian pendidikan pada FMIPA Universitas } \\
\text { Udayana sesuai dengan ketentuan yang ada }\end{array}$ \\
\hline & 11 & Program studi sesuai dengan pasar kerja/dunia usaha \\
\hline & 18 & Fakultas MIPA dapat meningkatkan pengetahuan mahasiswa \\
\hline & 22 & $\begin{array}{l}\text { Fakultas MIPA Universitas Udayana memiliki fasilitas perpustakaan, } \\
\text { laboratorium dan komputer }\end{array}$ \\
\hline & 19 & Keinginan berprestasi mahasiswa \\
\hline & 29 & Status akreditasi FMIPA \\
\hline \multirow[t]{4}{*}{2} & 25 & Saran dari rekan atau keluarga \\
\hline & 24 & Saran dari orang tua \\
\hline & 23 & Saran dari alumni \\
\hline & 27 & Mengetahui Udayana dari brosur \\
\hline \multirow[t]{7}{*}{3} & 5 & Masyarakat Bali yang ramah \\
\hline & 6 & Toleransi keagamaan yang tinggi \\
\hline & 4 & Jarang terjadi tindakan criminal \\
\hline & 7 & Biaya pendaftaran \\
\hline & 9 & Biaya pendidikan \\
\hline & 13 & Fakultas MIPA menyediakan berbagai beasiswa \\
\hline & 8 & Biaya hidup \\
\hline \multirow[t]{3}{*}{5} & 16 & Profesi orang tua \\
\hline & 15 & Pendidikan orang tua \\
\hline & 14 & Pendapatan orang tua \\
\hline \multirow[t]{2}{*}{6} & 20 & $\begin{array}{l}\text { Dorongan dari orang tua untuk melanjutkan pendidikan di perguruan } \\
\text { Tinggi }\end{array}$ \\
\hline & 21 & Harapan mudah memperoleh pekerjaan \\
\hline \multirow[t]{2}{*}{7} & 3 & Seni budaya Bali yang terkenal \\
\hline & 2 & Fakultas MIPA Universitas Udayana dekat dengan lokasi wisata \\
\hline \multirow[t]{2}{*}{8} & 12 & Standar nilai SNMPTN \\
\hline & 26 & informasi dari iklan di media massa dan elektronik \\
\hline
\end{tabular}

Sumber: Data Diolah, 2011 


\section{Kesimpulan}

Berdasarkan hasil dan pembahasan maka diperoleh kesimpulan bahwa dengan menggunakan rotasi promax dengan asumsi bahwa faktor-faktor yang digunakan berkorelasi diperoleh delapan faktor yang memengaruhi minat mahasiswa luar Bali kuliah di FMIPA Universitas Udayana Bali. Faktor-faktor tersebut yaitu: faktor pertama adalah faktor produk yang merupakan faktor dengan nilai eigen paling tinggi yaitu 7,792 dan varian $28,860 \%$, faktor kedua adalah faktor referensi dengan varian $8,732 \%$, faktor ketiga adalah faktor reputasi dengan varian $7,808 \%$, faktor keempat adalah faktor biaya dengan varian $6,723 \%$, faktor kelima adalah faktor latar belakang sosial ekonomi dengan varian 4,921\%, faktor keenam adalah faktor motivasi dengan varian 4,430\%, faktor ketujuh adalah faktor lokasi dengan varian 3,836\% dan faktor kedelapan adalah faktor promosi dengan varian $3,708 \%$, dengan total varian yang dapat dijelaskan adalah sebesar $69,018 \%$.

\section{Daftar Pustaka}

[1] Andrianto, H.N. 2008. "Minat dan Motivasi Mahasiswa Program Studi Seni Rupa Angkatan 2005-2007 Jurusan Seni dan Desain Fakultas Sastra Universitas Negeri Malang untuk Memilih Mata Kuliah Paket Desain Grafik dan Animasi”. Skripsi. Jurusan Seni dan Desain Program studi Pendidikan Seni Rupa Universitas Negeri Malang. Malang.

[2] Hair Jr., R. E. Anderson, R.L. Tathan, and W.C. Black. 1995. Multivariate Data Analysis with Readings. Prentice Hall.Inc. USA.

[3] Harahap, Novita. 2004. "Analisis Faktor-faktor yang Memengaruhi Keputusan Mahasiswa dalam Menempuh Pendidikan pada Politeknik LP3I Medan". Tesis. Program Pasca Sarjana Program Studi Ilmu Manajemen Universitas Sumatra Utara. Medan.

[4] Johnson, R.A. and Dean W. Wichern. 1998. Applied Multivariate Statistical Analysis. Prentice Hall International Inc. New Jersey.

[5] Kotler, Philip. 1995. Manajemen Pemasaran: Perencanaan, Implementasi dan Pengendalian. Edisi kedelapan. Salemba Empat. Jakarta. 